\title{
Intracranial Neurostimulation for Central Pain Relief
}

\section{Angelo Lavano*}

Department of Neurosurgery, School of Medicine and Surgery, University “Magna Graecia” of Catanzaro, Avenue Salvatore Venuta-88100, Catanzaro, Italy

\section{Editorial}

Central pain is an expression of a primary or secondary lesion or dysfunction of central nervous system and represents a very difficult condition to treat. Often pharmacotherapy allows a benefit clinically important only in a limited number of patients and clinical use of some drugs is rendered problematic by their poor handling and tolerability.

Intracranial neurostimulation represents a reversible method of functional neurosurgery, adaptable and free of major side effects, indicated in cases of intractable chronic pain when other conservative treatment modalities have been exhausted. Currently two types of intracranial neurostimulation are commonly used for control pain: deep brain stimulation (DBS) and motor cortex stimulation (MCS) [1].

The relief of pain with chronic electrical stimulation of deep sensory thalamic nuclei (DBS) was first reported by Mazars et al. and Hosobuchi et al. [2,3]. Although Europe and the United States over the past 20 years have been several interventions of deep brain stimulation for the treatment of chronic pain syndromes, this method over the years has been gradually replaced by less invasive as spinal cord stimulation, intrathecal infusion pumps and epidural cortical stimulation. Despite this trend, some conditions of chronic pain refractory to drugs still represent a valid indication. DBS may be employed for a number of nociceptive and neuropathic pain states, including cluster headaches, chronic low back pain, failed back surgery syndrome, peripheral neuropathic pain and facial deafferentation pain. Patients are selected for DBS for pain if they experienced chronic pain unresponsive to medical or surgical therapies over many years and to treatment administered during an admission to a pain clinic [4].

Pain pathways are very complex and DBS can modulate these mechanisms of transmission. The first pathway is composed of the spinothalamic tracts connecting the dorsal horn of the spinal cord to the ventral nuclei of the thalamus which project to the somatosensory cortices. The second pathway consists of tracts connecting the spine to the thalamus through the brain stem and the limbic system. Studies on deep brain stimulation for chronic pain in humans increased in the last years, thanks to the efficacy reported in various aetiologies including phantom limb pain $[5,6]$, brachial plexus injury $[7,8]$, central poststroke pain $[7,9]$, face pain $[10,11]$, spinal injuries or failed back surgery syndrome $[7,8]$.

DBS targets for pain are the septal region [12], the sensory thalamus (VPL and VPM) [6,7], the periventricular grey (PVG) and periaqueductal grey (PAG) [13], the internal capsule, the posterior hypothalamus, the nucleus accumbens [9] and the anterior cingulate cortex (ACC) [8]. Sensory thalamic stimulation is mainly used with varying effectiveness in several chronic pain syndromes with the VPM particularly targeted in facial pain. The VPM is found between the wall of the third ventricle and the internal capsule. The VPL is targeted 2-3 $\mathrm{mm}$ medial to the internal capsule for the arm pain, and 1-2 mm for the leg pain [10]. The PVG is placed $2-3 \mathrm{~mm}$ lateral to the third ventricle at the level of the posterior commissure and it is targeted for nociceptive pain states. Stimulation of this site also induces some changes of autonomic functions [14]. The stimulation of ACC is chosen in case of hemi- or whole-body post-stroke pain, although changes in psychological and motor functions have been observed. This surgical target is located $20 \mathrm{~mm}$ posterior to the anterior tip of the frontal horns of the lateral ventricles. Parameters of stimulation of PAG/PVG and sensory thalamus at low frequencies $(<50 \mathrm{~Hz})$ are generally analgaesic and at higher frequencies $(>70 \mathrm{~Hz})$ exacerbate pain [15]. The best parameters of stimulation of ACC are found to be $130 \mathrm{~Hz}, 450 \mu \mathrm{s}, 4-6.5$ $\mathrm{V}[8]$.

The mechanisms of action of DBS in the treatment of pain remain unclear : DBS might act, depending on the structure stimulated, either through inactivation by block neuronal depolarization or through a neuronal activation with increased release of inhibitory neurotransmitters. Whatever the mechanism of analgesia is, the effect of the stimulation is similar to the lesion, except for its reversibility and adaptability. In the stimulation of the somatosensory thalamic nuclei, electrical stimulation inhibits the abnormal neuronal activity that occurs in the VPM/VPL following their deafferentation. Moreover VPM stimulation may work through non-opioid mechanisms and offer some relief in central pain. In the stimulation of PVG (periventricular gray)/ PAG (periaqueductal grey), stimulation of these neuronal substrates leads to increased CSF levels of endogenous opioids (opioidergic mechanism) [16].

Side effects can occasionally occur in some DBS patients, including seizures, oculomotor symptoms (diplopia, vertical gaze paresis, blurred vision, oscillopsia) and headaches. Infections are also described. The majority of organisms were Staphylococcus species. Technical problems were reported in all studies, including migration of the electrode, skin erosion and fracture of the insulation. However the rate of these complications has decreased with the redesigned electrode $[1,17,18]$.

A meta-analysis of the literature has shown that $50 \%$ to $60 \%$ of DBS patients report at least moderate levels of pain relief and/or have continued stimulator use at one year follow-up. The stimulation of the thalamus is overall less effective while allowing better results in neuropathic pain as that of PVG/PAG has a greater efficiency (up to $79 \%$ ) above the nociceptive pain. The major indication for DBS is cancer pain and FBSS (67-78\% of long-term efficac) while recent data moderately support the use of DBS for post-stroke pain (long-term efficacy no more than 35) [19].

Chronic stimulation of the motorl cortex (MCS) for the treatment of pain was first reported by Tsubokawa in 1991 [20,21]. Afterwards MCS

*Corresponding author: Angelo Lavano, Professor, Department of Neurosurgery School of Medicine and Surgery, University "Magna Graecia" of Catanzaro Avenue Salvatore Venuta-88100, Catanzaro, Italy, Tel: +39 09613647389, +39 09613647385; Fax: +3909613647118, +3909613647092; E-mail: lavano@unicz.it, angelolavano@gmail.com

Received October 15, 2015; Accepted October 15, 2015; Published October 22 2015

Citation: Lavano A (2015) Intracranial Neurostimulation for Central Pain Relief Pain Manage Med 1: e102.

Copyright: (c) 2015 Lavano A. This is an open-access article distributed under the terms of the Creative Commons Attribution License, which permits unrestricted use, distribution, and reproduction in any medium, provided the original author and source are credited. 
was used for intractable pain syndromes including post-stroke pain, phantom limb pain, spinal cord injury pain, postherpetic neuralgia and trigeminal neuropathic pain. By the time the MCS indications have been extended to various types of peripheral and central deafferentation pain refractory to common treatments included, when indicated, spinal cord stimulation.

The mechanisms underlying the effects of MCS is actually still unknown. A corticospinal system relatively intact is necessary, but not sufficient, to achieve pain control with MCS, while success in treating MCS does not require an intact somatosensory system. It has been proposed that the action mechanism of MCS may act by reinforcing the control of non-nociceptive sensory inputs on nociceptive systems at the level of the thalamus, dorsal column nuclei and spinal cord. Other proposed mechanisms involve supraspinal structures (cingulate gyrus, orbitofrontal cortex and brainstem). MCS-induced pain relief is associated with an improved sensory discrimination within the painful zone suggesting that MCS acts on somatosensory pathways and sensory processing [22]

Reported amplitudes range from $0.5 \mathrm{~V}$ to $10 \mathrm{~V}$, rates from $5 \mathrm{~Hz}$ to $130 \mathrm{~Hz}$ and pulse widths from $60 \mu$ s to $450 \mu$ s, increasing the intensity by $20 \%$ if necessary [23].

The surgical risks of MCS are rare and include epidural intracranial bleeding and infection. Seizures induction has been reported following MCS programming and during chronic MCS, not necessary leading to the development of epilepsy [24].

MCS has proven effective in several intractable chronic pain conditions. Scientific studies confirm that the different forms of central pain and peripheral neuropathic pain can be effectively treated with MCS. A review of the literature reports patients with neuropathic facial pain achieved $\geq 50 \%$ pain relief with MCS. Post-stroke pain responds nearly as well, with almost two-thirds of patients obtaining good to excellent relief $[25,26]$.

In conclusion the methods of brain electrical stimulation applied to the treatment of chronic pain, both as regards the DBS that MCS, certainly represent a research field to be explored and the interest of functional neurosurgery is likely to increase with the development of methods of functional neuroradiology (PET, functional MRI) that allow us to study the pathways that are at the basis of many chronic pain conditions.

The research for new targets in areas that control the processing of affective behavioral pain may represent the natural development of these methods in the treatment of other types of chronic pain in which the "central" character seems to overcome its peripheral origin (centralization of chronic pain), as in facial pain syndromes resulting from peripheral damage of the distal branches of the trigeminal nerve (atypical facial neuralgia).

\section{References}

1. Levy R, Deer TR, Henderson J (2010) Intracranial neurostimulation for pain control: a review. Pain Physician 13: 157-165.

2. Mazars G, Mérienne L, Ciolocca C (1973) [Intermittent analgesic thalamic stimulation. Preliminary note]. Rev Neurol (Paris) 128: 273-279.

3. Hosobuchi Y, Adams JE, Rutkin B (1973) Chronic thalamic stimulation for the control of facial anesthesia dolorosa. Arch Neurol 29: 158-161.

4. Garonzik I, Samdani A, Ohara S, Lenz FA (2001) Deep brain stimulation for the control of pain. Epilepsy \& Behavior: S55-S60.

5. Yamamoto T, Katayama Y, Obuchi T, Kano T, Kobayashi K, et al. (2006) Thalamic sensory relay nucleus stimulation for the treatment of peripheral deafferentation pain. Stereotact Funct Neurosurg 84: 180-183.
6. Pereira EA, Boccard SG, Linhares P, Chamadoira C, Rosas MJ, et al. (2013) Thalamic deep brain stimulation for neuropathic pain after amputation or brachial plexus avulsion. Neurosurg Focus 35: E7.

7. Boccard SG, Pereira EA, Moir L, Aziz TZ, Green AL (2013) Long-term outcomes of deep brain stimulation for neuropathic pain. Neurosurgery 72 : 221-230.

8. Boccard SG, Fitzgerald JJ, Pereira EA (2014) Targeting the affective component of chronic pain: a case series of deep brain stimulation of the anterior cingulate cortex. Neurosurgery 74: 628-635.

9. Mallory GW, Abulseoud O, Hwang SC, Gorman DA, Stead SM, et al. (2012) The nucleus accumbens as a potential target for central poststroke pain. Mayo Clin Proc 87: 1025-1031.

10. Hosobuchi Y, Adams JE, Linchitz R (1977) Pain relief by electrical stimulation of the central gray matter in humans and its reversal by naloxone. Science 197: 183-186.

11. Broggi G, Franzini A, Leone M, Bussone G (2007) Update on neurosurgica treatment of chronic trigeminal autonomic cephalalgias and atypical facia pain with deep brain stimulation of posterior hypothalamus: results and comments. Neurol Sci 28 Suppl 2: S138-145.

12. Gol A (1967) Relief of pain by electrical stimulation of the septal area. J Neurol Sci 5: $115-120$

13. Richardson DE, Akil H (1977) Long term results of periventricular gray selfstimulation. Neurosurgery 1: 199-202.

14. Pereira EA, Lu G, Wang S, Schweder PM, Hyam JA, et al. (2010) Ventral periaqueductal grey stimulation alters heart rate variability in humans with chronic pain. Exp Neurol 223: 574-581.

15. Pereira EA, Aziz TZ (2014) Neuropathic pain and deep brain stimulation. Neurotherapeutics 11: 496-507.

16. Boccard SG, Pereira EA, Aziz TZ2 (2015) Deep brain stimulation for chronic pain. J Clin Neurosci 22: 1537-1543

17. Coley E, Farhadi R, Lewis S (2009) The incidence of seizures following deep brain stimulating electrode implantation for movement disorders, pain and psychiatric conditions. Br J Neurosurg 23: 179-183.

18. Fridley J, Adams G, Sun P, York M, Atassi F, et al. (2013) Effect of subthalamic nucleus or globus pallidus interna stimulation on oculomotor function in patients with Parkinson's disease. Stereotact Funct Neurosurg 91: 113-121.

19. Levy RM1 (2003) Deep brain stimulation for the treatment of intractable pain. Neurosurg Clin N Am 14: 389-399, vi.

20. Tsubokawa T, Katayama Y, Yamamoto T, Hirayama T, Koyama S (1991) Chronic motor cortex stimulation for the treatment of central pain. Acta Neurochir Suppl (Wien) 52: 137-139.

21. Tsubokawa T, Katayama Y, Yamamoto T, Hirayama T, Koyama S (1991) Treatment of thalamic pain by chronic motor cortex stimulation. Pacing Clin Electrophysiol 14: 131-134.

22. Lazorthes Y, Sol JC, Fowo S, Roux FE, Verdié JC (2007) Motor cortex stimulation for neuropathic pain. Acta Neurochir Suppl 97: 37-44.

23. Bonicalzi V, Canavero S (2004) Motor cortex stimulation for central and neuropathic pain (Letter regarding Topical Review by Brown and Barbaro) Pain 108: 199-200.

24. Bezard E, Boraud T, Nguyen JP, Velasco F, Keravel Y, et al. (1999) Cortica stimulation and epileptic seizure: a study of the potential risk in primates. Neurosurgery 45: 346-350.

25. Nguyen JP, Lefaucher JP, Le Guerinel C, Eizenbaum JF, Nakano N, et al (2000) Motor cortex stimulation in the treatment of central and neuropathic pain. Arch Med Res 31: 263-265.

26. Nguyen JP, Lefaucheur JP, Decq P, Uchiyama T, Carpentier A, et al. (1999) Chronic motor cortex stimulation in the treatment of central and neuropathic pain. Correlations between clinical, electrophysiological and anatomical data. Pain 82: 245-251. 